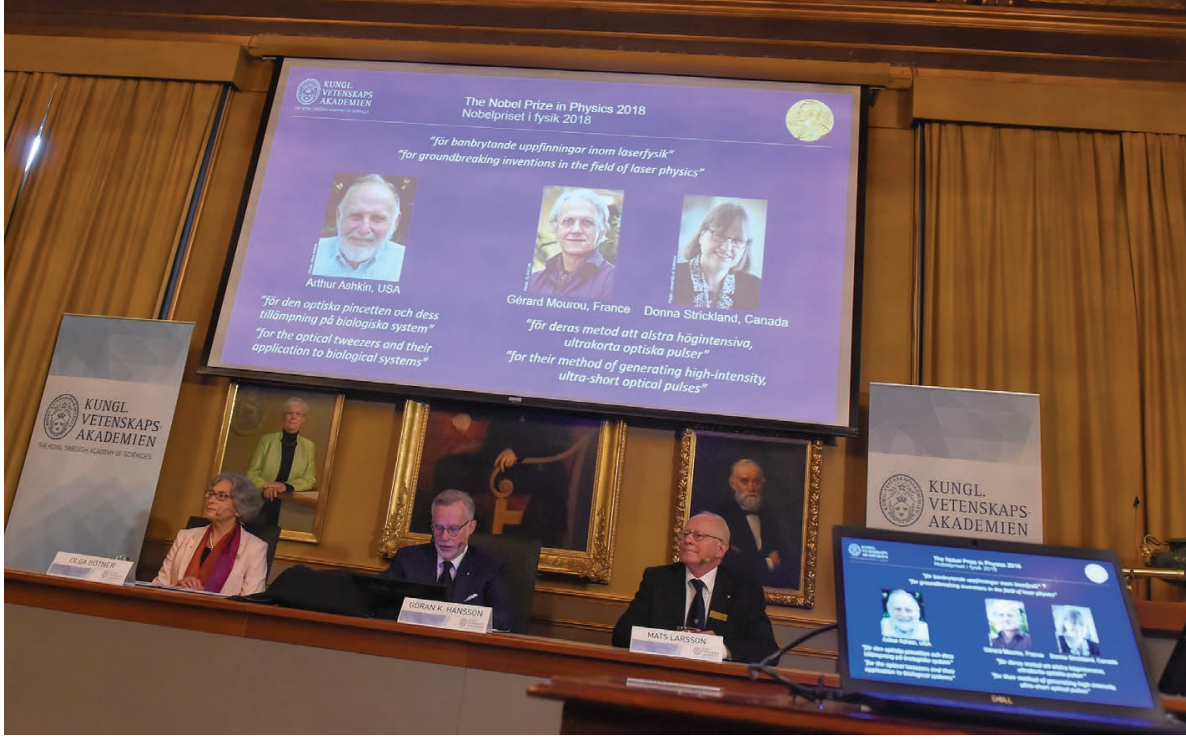

Members of the Nobel committee for physics announce this year's prize.

PRIZES

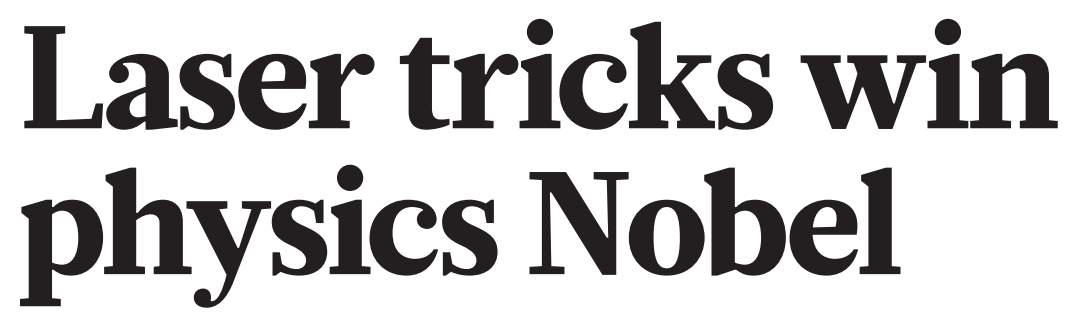

Laureates include first female winner in 55 years.

BY DAVIDE CASTELVECCHI, ELIZABETH GIBNEY \& MATTHEW WARREN

A trio of laser scientists has won the 2018 Nobel Prize in Physics for work using intense beams to capture superfast processes and to manipulate tiny objects. The laureates include Donna Strickland, who is the first woman to win the award in 55 years.

Strickland, at the University of Waterloo, Canada, shares half of the prize, worth 9 million Swedish krona (US\$1 million), with her former supervisor, Gérard Mourou, now at the École Polytechnique in Paris. Arthur Ashkin, at Bell Laboratories in Holmdel, New
Jersey, won the other half of the prize.

Strickland and Mourou pioneered a way to produce the shortest, most-intense pulses of light ever created. These are now used throughout science to unravel processes that previously appeared instantaneous, such as the motion of electrons within atoms. Ashkin won the prize for developing 'optical tweezers', beams of laser light that can grab and control microscopic objects such as viruses and cells.

"First of all, you have to think it's crazy, so that was my first thought," said Strickland during the announcement of the prizes on 2 October. "And you do always wonder if it's real."

Strickland is the third woman ever to win the
Nobel Prize in Physics; the last female scientist $\succ$ to win it was Maria Goeppert Mayer, in 1963. "I don't know what to say, I'm honoured to be one of those women," said Strickland. Göran K. Hansson, secretary general of the Royal Swedish Academy of Sciences in Stockholm, said the academy is "taking measures" to encourage more nominations of female scientists, but that those measures did not affect this year's prize.

\section{POWERFUL PULSES}

Short-lived laser pulses allow scientists to spy on processes that are over in a heartbeat. But before Strickland and Mourou's technique, the intensity of such pulses was limited because the high power risked destroying the amplifier needed to create them. The pair's breakthrough was to stretch out a laser pulse in time. This reduced the power of the light and made it possible to use conventional amplifiers, before the pulse is squeezed back together. Because fleeting pulses cause less damage, they have also found uses in laser eye surgery. "Nobels are awarded for a discovery or an invention. This really bridges the two," says John Dudley, an optical physicist at the University of Franche-Comté in Besançon, France.

At 96, Ashkin is the oldest-ever Nobel laureate. His prize-winning work began immediately after the laser's invention, in 1960. Lasers exert a gentle pressure, which Ashkin realized could be used to manipulate tiny objects without damaging them. His experiments with micrometresized spheres showed that the particles were drawn to the highest-intensity region in a beam of light. This led to a way to sculpt lasers to trap, levitate and move objects. Ashkin discovered that these 'optical tweezers' could capture bacteria, viruses and living cells. Miles Padgett, an optical physicist at the University of Glasgow, UK, says that the impact of Ashkin's work has been universally recognized. Today, optical tweezers are used in myriad applications, from separating healthy blood cells from infected ones to engineering nanoscale materials. .

\title{
Cancer immunologists scoop medicine Nobel prize
}

\section{One of the hottest areas in cancer research, immunotherapy can dramatically extend lives.}

\section{BY HEIDI LEDFORD, HOLLY ELSE AND MATTHEW WARREN}

$\mathrm{T}$ Iwo scientists who pioneered a new way to treat cancer have won the 2018 Nobel Prize in Physiology or Medicine. James Allison at the University of Texas MD Anderson
Cancer Center in Houston and Tasuku Honjo at Kyoto University in Japan showed how proteins on immune cells can be used to manipulate the immune system so that it attacks cancer cells. The approach has led to therapies that have extended lives, and even wiped out all signs of disease in some people with advanced cancers.
"To have my work really impact people is one of the best things I could think about," said Allison at a press conference on 1 October, the day the 9-million-Swedish-krona (US\$1-million) prize was announced. "It's everybody's dream."

In the 1990s, Allison, then at the University of California, Berkeley, studied a protein, 

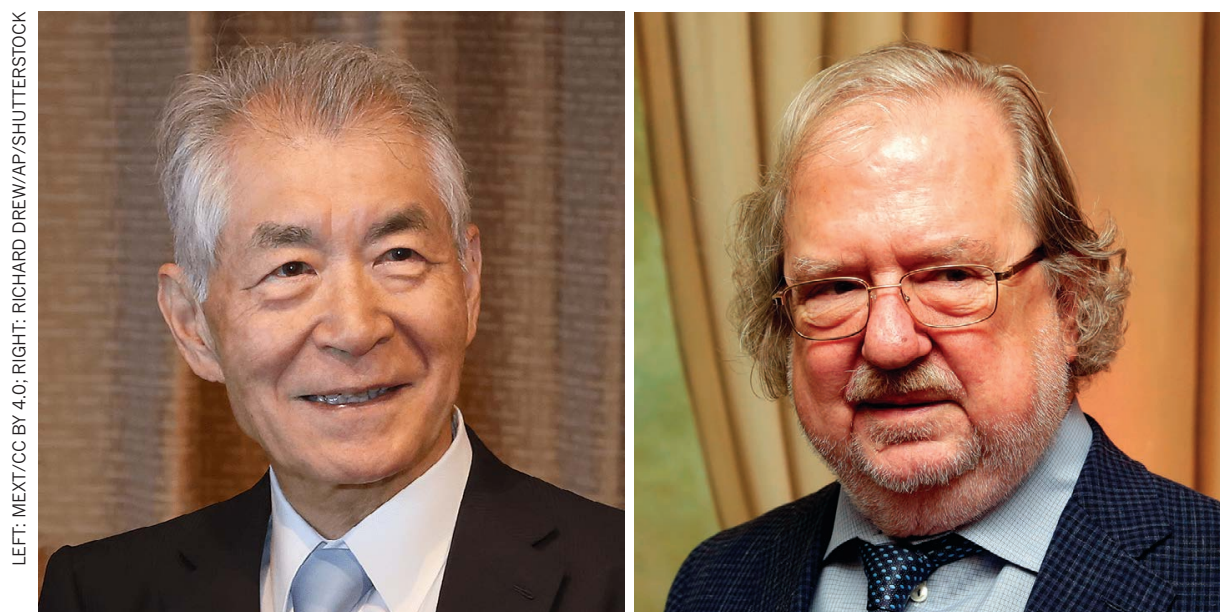

Tasuku Honjo (left) and James Allison share the 2018 Nobel Prize in Physiology or Medicine.

CTLA-4, that acts as a brake on immune cells called T cells. In 1997, he and his colleagues engineered an antibody that binds to CTLA-4, unleashing $\mathrm{T}$ cells to attack cancer in mice. A clinical study in 2010 found that the antibody had a striking effect on people with advanced melanoma, a form of skin cancer ${ }^{1}$.

Working independently of Allison, in 1992, Honjo discovered the T-cell protein PD-1, which acts as a brake on the immune system by a different mechanism. Research showed the protein to be highly effective against several human cancers, including lung cancer ${ }^{2}$. Some people with metastatic cancer went into longterm remission, raising the possibility of a cure.

Clinical work on 'immune checkpoint therapy' has since developed apace. Treatments that block PD-1 have proved to be effective in lung and renal cancers, lymphomas and melanoma. And combined therapies that target CTLA-4 and PD-1 in people with melanoma showed that this approach can be even more effective than CTLA- 4 alone ${ }^{3}$. Trials are now under way to evaluate the efficacy of checkpoint therapy against most types of cancer, and scientists are looking for other checkpoint protein targets.

Others also made important early discoveries about checkpoint inhibitors, notes Gordon Freeman, an immunologist at the Dana-Farber Cancer Institute in Boston, Massachusetts, who was disappointed not to be recognized. Freeman, along with immunologists Arlene Sharpe at Harvard Medical School in Boston and Lieping Chen at Yale University in New Haven, Connecticut, also studied checkpoint proteins, and a molecule that binds to PD-1, PD-L1. The US Food and Drug Administration has since approved drugs that target PD-1 and PD-L1.

But immunologist Jerome Galon of the French national biomedical research agency, INSERM, in Paris, describes Honjo and Allison as "the obvious two first choices".

The immune approach to fighting cancer has come a long way. Allison met with considerable resistance when he first tried to get pharmaceutical companies interested. But in 2012, when PD-1 inhibitors were shown to work against lung cancer, the field ignited.

It's been thrilling to watch the field develop, says Freeman. "It's wonderful because so many cancer patients are doing better."

1. Hodi, F. S. et al. N. Engl. J. Med. 363, 711-723 (2010).

2. Topalian, S. L. et al. N. Engl. J. Med. 366, 2443-2454 (2012).

3. Larkin, J. et al. N. Engl. J. Med. 373, 23-34 (2015). 